Review

\title{
Mesenchymal stromal cells promote liver regeneration through regulation of immune cells
}

\author{
Chenxia $\mathrm{Hu}$, Zhongwen $\mathrm{Wu}$ and Lanjuan $\mathrm{Li}^{凶}$ \\ Collaborative Innovation Center for Diagnosis and Treatment of Infectious Diseases, State Key Laboratory for Diagnosis and Treatment of Infectious Diseases, \\ First Affiliated Hospital, School of Medicine, Zhejiang University, Hangzhou, Zhejiang, PR China \\ $\triangle$ Corresponding author: Email: 1jli@zju.edu.cn; Telephone: +86-571-8723 6759; Fax: +86-571-8723 6755 \\ (1) The author(s). This is an open access article distributed under the terms of the Creative Commons Attribution License (https://creativecommons.org/licenses/by/4.0/). \\ See http://ivyspring.com/terms for full terms and conditions.
}

Received: 2019.11.13; Accepted: 2019.12.26; Published: 2020.01.22

\begin{abstract}
The liver is sensitive to pathogen-induced acute or chronic liver injury, and liver transplantation (LT) is the only effective strategy for end-stage liver diseases. However, the clinical application is limited by a shortage of liver organs, immunological rejection and high cost. Mesenchymal stromal cell (MSC)-based therapy has gradually become a hot topic for promoting liver regeneration and repairing liver injury in various liver diseases, since MSCs are reported to migrate toward injured tissues, undergo hepatogenic differentiation, inhibit inflammatory factor release and enhance the proliferation of liver cells in vivo. MSCs exert immunoregulatory effects through cell-cell contact and the secretion of anti-inflammatory factors to inhibit liver inflammation and promote liver regeneration. In addition, MSCs are reported to effectively inhibit the activation of cells of the innate immune system, including macrophages, natural killer (NK) cells, dendritic cells (DCs), monocytes and other immune cells, and inhibit the activation of cells of the adaptive immune system, including T lymphocytes, B lymphocytes and subsets of T cells or B cells. In the current review, we mainly focus on the potential effects and mechanisms of MSCs in inhibiting the activation of immune cells to attenuate liver injury in models or patients with acute liver failure (ALF), nonalcoholic fatty liver disease (NAFLD), and liver fibrosis and in patients or models after LT. We highlight that MSC transplantation may replace general therapies for eliminating acute or chronic liver injury in the near future.
\end{abstract}

Key words: liver transplantation, mesenchymal stromal cell, liver regeneration, immunoregulation, anti-inflammation

\section{Introduction}

Early in 1931, it was demonstrated that the liver is a unique organ able to regenerate completely after removal of two-thirds of the liver mass in rats [1]. The liver is composed of primary hepatocytes, cholangiocytes, Kupffer cells (KCs), liver sinusoidal endothelial cells, hepatic stellate cells (HSCs), fibroblasts, lymphatic vessel cells, oval cells, lymphocytes and other immune cells $[2,3]$. The cell death of hepatocytes and/or cholangiocytes subsequently triggers the activation of $\mathrm{KCs}$, liver sinusoidal endothelial cells and HSCs [4, 5]. Furthermore, other liver-specific immune cells, such as dendritic cells (DCs), natural killer (NK) cells, natural killer T cells (NKT) cells, and neutrophils, also respond to liver injury and subsequently produce cytokines and initiate anti-inflammatory responses [6]. The blood supply of the liver moves through the hepatic artery and portal vein, which screen for systemic and gut-derived pathogens or toxins; thus, the liver is sensitive to pathogens that induce acute or chronic liver injury [7]. At present, liver transplantation (LT) is still the only curative treatment for end-stage liver diseases [8], while the clinical application is limited by a shortage of liver organs, immunological rejection and high costs.

Mesenchymal stromal cell (MSC)-based therapy has gradually become a hot topic since MSCs are able to promote liver regeneration and attenuate liver injury after administration in vivo. MSCs can be isolated from multiple organs and tissues, including 
bone marrow, adipose tissue, peripheral blood, synovial membrane tissue, and cartilage [9]. They are able to give rise to mesodermal lineages including adipocytes, osteocytes and chondrocytes [10]. Moreover, transplanted MSCs take part in liver regeneration by migrating toward injured tissues, participating in hepatocyte differentiation and paracrine mechanisms and having immunomodulatory properties [11-13]. In vitro culture with specific growth factors promoted the hepatogenic differentiation of MSCs into hepatocyte-like cells (HLCs) with liver-specific morphology and liver functions, including abilities to uptake low-density lipoprotein and indocyanine green, secrete albumin and urea, and store glycogen and the cells also had cytochrome P450 activity [14]. In vivo, intrasplenic transplanted MSCs engrafted into carbon tetrachloride $\left(\mathrm{CCl}_{4}\right)$-treated liver tissues underwent hepatogenic differentiation into HLCs with typical hepatocyte morphology and formed a three-dimensional architecture [15]. Furthermore, engrafted MSCs that had underwent hepatogenic differentiation further attenuated hepatocyte necrosis and promoted liver regeneration, subsequently improving the survival rate of ALF models after transplant into injured liver tissue [16]. Administration of HLCs before partial hepatectomy significantly downregulated lipid accumulation and hepatocyte apoptosis and improved the survival rate of ALF animal models [17]. However, Di Bonzo et al. showed that engrafted MSCs rarely undergo hepatogenic differentiation and disappear from the liver after injection within one month [18]. MSCs are able to synthesize various growth factors and cytokines to exert paracrine effects in liver tissues to promote liver regeneration. MSCs secrete a large number of antiapoptotic growth factors, such as stromal cell-derived factor-1, vascular endothelial growth factor, hepatocyte growth factor and insulin-like growth factor-I, to prevent HSC activation and subsequent liver fibrosis [19]. Moreover, MSC-derived growth factors such as hepatocyte growth factor, fibroblast growth factor, interleukin (IL)-6, fibrinogen and transforming growth factor (TGF)-a also participate in liver regeneration by promoting hepatocyte proliferation [20]. They also decrease the expression of pro-inflammatory factors, including tumor necrosis factor- $\alpha$ (TNF)- $\alpha$, interferon (IFN) $-\gamma$ and IL-1 $\beta$, and the expression of chemokines, including CXCL1 and CXCL2, in vivo to attenuate liver inflammation [21, 22]. The paracrine mechanisms of MSCs in liver diseases are reviewed elsewhere [23]. Interestingly, the immunoregulation of MSCs has gradually drawn attention since they effectively inhibit the activation of innate immune cells and activate cells of the adaptive immune system, including $\mathrm{T}$ lymphocytes, regulatory $\mathrm{T}$ cells (Tregs), $\mathrm{T}$ helper cells, B lymphocytes and regulatory B cells (Bregs). Consequently, MSCs generate a tolerogenic environment for maintaining immune homeostasis in vivo. In the current review, we mainly focus on the potential effects and mechanisms of MSCs in inhibiting the activation of immune cells to attenuate liver injury in models or patients with acute liver failure (ALF), nonalcoholic fatty liver disease (NAFLD), and liver fibrosis and in patients or models after LT.

\section{Liver regeneration and immune cells}

In response to liver injury, liver tissues initiate subsequent activation of several subsets of innate immune cells, including macrophages, NK cells, NKT

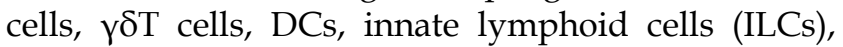
neutrophils, eosinophils and adaptive immune cells, including T lymphocytes, Tregs, B lymphocytes, Bregs and T helper (Th) cells (Figure 1).

Wang et al. demonstrated that a subset of F4/80hiGATA6 ${ }^{+}$macrophages could be recruited from the peritoneal cavity into the liver and further exert their pivotal reparative ability for promoting liver regeneration [24]. Furthermore, circulating macrophages are reported to promote the vascularization of liver endothelial cells for liver regeneration [25]. Liver-specific macrophages (KCs) represent approximately $20 \%$ of the liver nonparenchymal cells and serve as the immune barrier for liver tissue and alert other immune cells through intricate cell-cell interactions and the secretion of cytokines [26]. In response to liver injury, KCs subsequently generate a variety of cytokines and chemokines, including TNF- $\alpha$, CCL2, CCL5, interleukin (IL)-1, and IL-6, recruit other immune cells into liver tissue to promote liver regeneration [27, 28]. NK cells are reported to constitute $30 \% \sim 50 \%$ of the intrahepatic lymphocytes in humans, and they play critical roles in controlling bacterial and viral infections in the liver [29]. However, other studies debate the protective effects of NK cells in animal models, as they have shown that excessive activation of hepatic NK cells leads to high serum levels of IFN- $\gamma$ and inhibition of liver regeneration [30, 31]. In general, NKT cells can be categorized into pro-inflammatory type I NKT cells and anti-inflammatory type II NKT cells [32], and the two types of NKT cells serve as protective or pathogenic immune cells by inhibiting virus replication or inducing hepatocyte apoptosis and pro-inflammatory cytokine secretion [33-35]. However, there is debate about the functions of NKT cells according to a current study. Hosoya et al. showed that NKT cells 
were not very potent in liver regeneration since CD1d-/- or Ja281-/- mice demonstrated a comparable regeneration rate to wild-type mice after partial hepatectomy [36]. $\gamma \delta T$ cells, which constitute approximately $15 \% \sim 25 \%$ of liver $\mathrm{T}$ cells, also serve as a protective or pathogenic immune cell in liver diseases. IFN- $\gamma$-producing $\gamma \delta T$ cells triggered the apoptosis of hepatocytes, while IL-17-producing $\gamma \delta T$ cells exerted protective effects via inhibition of other immune cells and promotion of the apoptosis of fibrogenic HSCs [37]. Partial hepatectomy significantly upregulated the number of IL-17-producing $\gamma \delta T$ cells, further promoted the secretion of IL- 6 and inhibited the secretion of IFN- $\gamma$ for liver regeneration [38]. DCs in liver tissue are divided into two subsets, plasmacytoid DCs (pDCs), which express low levels of MHC-II, and classical DCs (cDCs), which express high levels of MHC-II. Thus, pDCs are limited in presenting antigens, and cDCs are professional antigen-presenting cells [39]. Partial hepatectomy dramatically increased the liver DC number and the level of DC-derived TNF- $\mathrm{a}$, thus enhancing the secretion of IL-10 but inhibiting the secretion of IFN- $\gamma$ from $\mathrm{T}$ cells for liver regeneration $[40,41]$. Hepatic CD49a+ type 1 innate lymphoid cells (ILC1s) limited the recruitment of peripheral NK cells and generated a tolerogenic liver organ to confront various kinds of viral infections [42]. Moreover, ILC1s significantly improved the secretion of IL-22 for liver regeneration in response to partial hepatectomy [43]. Neutrophils migrate to the injured site of the liver and aggravate liver injury after the generation of reactive oxygen species, pro-inflammatory factors and elastase, while the liver initiates a recovery mechanism after clearing inflammatory neutrophils [44]. Activated eosinophils are able to secrete cytokines, cytotoxic granule proteins, enzymes and lipid mediators to cleave pathogens in vivo [45]. Furthermore, IL-4 secreted from eosinophils was the central factor promoting the proliferation of quiescent hepatocytes in models of partial hepatectomy and toxin treatment, while eosinophil-lacking mice showed a compromised regeneration rate in the liver [46].

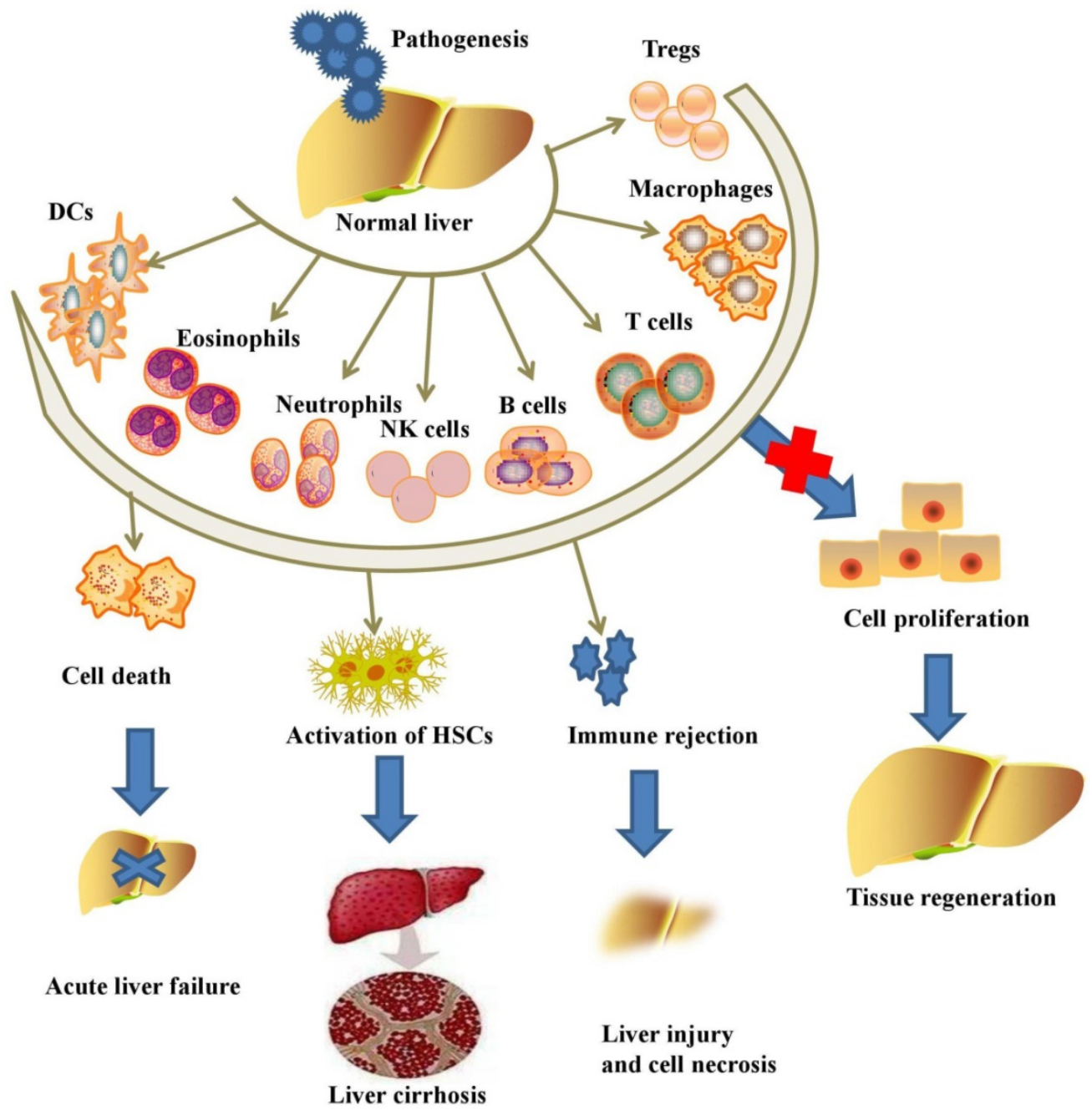

Figure 1. Pathogens initiate the activation of inflammatory immune cells and aggravate acute or chronic liver injury, while the inhibition of immune cells promotes liver regeneration. 
In response to IL-6 and other inflammatory factors, $\mathrm{T}$ cell differentiation is initiated to augment antiviral adaptive immune responses and mitigate $\mathrm{T}$ cell toxicity [47]. Tumanov et al. demonstrated that surface lymphotoxin secreted from $\mathrm{T}$ cells plays a critical role in liver regeneration, while a deficiency of $\mathrm{T}$ cells in mice leads to serious liver injury and reduced DNA synthesis after partial hepatectomy [48]. In addition, both Tregs and Th17 cells are subsets of CD4+ Th cells that help to prevent immune response-induced liver injury [49, 50]. B cells are critical in liver regeneration after partial hepatectomy since the adoptive transfer of $\mathrm{B}$ cells increased lymphotoxin beta production and successfully rescued defective liver regeneration [51]. Furthermore, the recruitment of innate-like Bregs and MZ-like B cells from the spleen and peritoneal cavity into liver tissue contributes to the elimination of liver injury [52].

Although external pathogens and immune system imbalances induce liver inflammation and liver injury, the inhibition of immune cell activation contributes to liver repair and liver regeneration.

\section{MSC transplantation promotes liver regeneration in partial hepatectomy (PH) models}

The liver is able to spontaneously regenerate after liver resection, and quiescent hepatocytes and cholangiocytes, which stay in the $\mathrm{G}_{0}$ phase of the cell cycle, will undergo proliferation for compensation of lost cells in response to $\mathrm{PH}$ [2]. Thus, the PH model serves as a standard model for exploring potential mechanisms in liver regeneration. Spontaneous liver regeneration is divided into three stages, the initiation, proliferation, and termination phases after $\mathrm{PH}$, and it is regulated by a complex interactive network consisting of liver cells and extrahepatic organs. In addition, various growth factors, cytokines, hormones, metabolic networks, oxidative stress products, and microRNAs are essential for improving liver regeneration and maintaining hepatic mass [2].

Current studies have shown that MSCs are able to stimulate liver regeneration after surgical resection via promotion of cellular proliferation, downregulation of fat accumulation and paracrine mechanisms. Although MSCs are distributed in multiple tissues, including the brain, thymus, heart, liver, and lung, $\mathrm{PH}$ has been shown to induce the migration of MSCs into liver tissue to promote liver regeneration [53]. Although a small portion of MSCs are able to engraft in liver tissue, they persist in liver tissue for up to 60 days post-transplantation after $20 \%$ liver hepatectomy. Transplanted MSCs undergo hepatogenic differentiation mainly in the periportal area of the injured liver [54]. MSC transplantation significantly attenuated metabolic dysfunction and improved liver regeneration by upregulating the proliferation of hepatocytes and sinusoidal endothelial cells, decreasing hepatocyte fat accumulation and decreasing serum levels of IL-6, HGF, and IL-10 in PH-treated mice [55]. In addition, MSCs also improved liver regeneration and restored liver function in the $\mathrm{PH}$ model partly via mechanistic target of rapamycin (mTOR) signaling and improved lipid $\beta$-oxidation. In addition, MSCs further activated the STAT3 and Hippo-YAP pathways to improve hepatocyte proliferation for liver regeneration [56]. Preoperative resveratrol administration enhanced the homing capacity of MSCs into liver tissue, thus decreasing the expression of TNF- $\alpha$ and IL-6 and improving liver regeneration in $\mathrm{PH}$-treated rats [57]. In a $90 \% \mathrm{PH}$ model, MSCs were proven to improve the glucose metabolism and survival rate of rats with PH-induced ALF via promotion of hepatocyte proliferation through the AKT/GSK-3 $\beta / \beta$-catenin pathway [58]. Moreover, implantation of bioencapsulated MSCs promoted liver regeneration and increased the survival rate of $90 \% \mathrm{PH}$-treated rats from $21 \%$ to $91 \%$ via induction of hepatogenic differentiation and the secretion of growth factors [59]. On the other hand, the MSC-derived secretome promotes liver regeneration, as shown by the increase in the liver-to-body weight ratio and hepatocyte proliferation seen in $\mathrm{PH}$ models at an early stage after surgical resection [60].

MSCs not only improved liver regeneration in $\mathrm{PH}$ models but also increased hepatocyte proliferation and liver regeneration in $\mathrm{PH}$ models with background diseases. Intriguingly, MSCs improved liver function and liver regeneration in repeated $\mathrm{PH}$ models after upregulation of HGF expression and attenuation of hepatic vacuolar degeneration [61]. In a partial I/R and PH mouse model, human MSCs significantly decreased I/R-induced injury, hindered hepatocellular apoptosis and promoted liver regeneration [62]. Although hepatic steatosis significantly inhibited the endogenous regenerative process after $\mathrm{PH}$, MSC transplantation improved liver regeneration and hepatocyte proliferation but decreased hepatocyte apoptosis through paracrine mechanisms [63]. MSCs that grow and proliferate will be able to persistently and functionally fulfill the need for regeneration in injured livers after clarification of the related mechanisms in more liver injury models.

\section{Immunoregulation of MSCs in treating liver diseases}

Although no study demonstrated that MSC transplantation participated in immunoregulation in 
PH models, MSCs have been further proven to repair liver injury by immunoregulation in various liver diseases. MSCs are able to suppress the proliferation, pro-inflammatory cytokine secretion and maturation of immune cells, thus protecting against liver injury in various liver diseases (Table 1). MSCs exert immunomodulatory effects in liver diseases through cell-cell interactions and the secretion of anti-inflammatory factors (Figure 2).

Table 1. MSCs exert immunoregulation in the treatment of ALF, NAFLD, and liver fibrosis patients and recipients of LT.

\begin{tabular}{|c|c|c|c|c|c|c|}
\hline Modification & $\begin{array}{l}\text { MSC } \\
\text { source }\end{array}$ & Model & Pathogenesis & Mechanism & Effect & Ref. \\
\hline N/A & $\begin{array}{l}\text { Bone } \\
\text { marrow }\end{array}$ & Mouse & $\mathrm{CCl} 4$ & IL-17-producing NKT cells $\downarrow$; FoxP3+IL-10+ NKT cells $\uparrow$ & $\begin{array}{l}\text { Liver injury } \downarrow \text {; liver inflammatory cell } \\
\text { infiltration } \downarrow\end{array}$ & [73] \\
\hline N/A & $\begin{array}{l}\text { Bone } \\
\text { marrow }\end{array}$ & Mouse & TAA & $\begin{array}{l}\text { Incidence of cell death } \downarrow \text {; hepatocyte cytoplasmic vacuolization } \downarrow \text {; } \\
\text { macrophage infiltration } \downarrow\end{array}$ & $\begin{array}{l}\text { Liver histopathology } \downarrow \text {; survival time of } \\
\text { ALF mice } \uparrow\end{array}$ & [72] \\
\hline N/A & $\begin{array}{l}\text { Bone } \\
\text { marrow }\end{array}$ & Mouse & ConA & NKT activation $\downarrow$; lymphocyte proliferation $\downarrow$ & Liver damage $\downarrow$ & {$[109$} \\
\hline N/A & $\begin{array}{l}\text { Bone } \\
\text { marrow }\end{array}$ & Mouse & ConA & TNF- $a+$ NKT cells $\downarrow ;$ IFN- $\gamma+$ NKT cells $\downarrow ;$ IL-4+ NKT cells $\downarrow$ & Liver damage $\downarrow$ & [75] \\
\hline N/A & $\begin{array}{l}\text { Adipose } \\
\text { tissue }\end{array}$ & Mouse & ConA & CD11b+Gr-1+F4/80+ cells $\downarrow$ & $\begin{array}{l}\text { Serum ALT and LDH activity } \downarrow ; \\
\text { hepatocyte necrosis } \downarrow\end{array}$ & [76] \\
\hline $\begin{array}{l}\text { Overexpression } \\
\text { of IL-35 }\end{array}$ & $\begin{array}{l}\text { Adipose } \\
\text { tissue }\end{array}$ & Mouse & ConA & IFN- $\gamma^{+}$liver mononuclear cells $\downarrow$ & $\begin{array}{l}\text { Hepatocyte apoptosis } \downarrow \text {; survival rate of } \\
\text { ALF mice } \uparrow\end{array}$ & {$[78]$} \\
\hline N/A & $\begin{array}{l}\text { Bone } \\
\text { marrow }\end{array}$ & Mouse & a-GalCer & TNF- $a+$ NKT cells $\downarrow ;$ IFN- $\gamma+$ NKT cells $\downarrow ;$ IL-4+ NKT cells $\downarrow$ & Liver damage $\downarrow$ & [75] \\
\hline N/A & $\begin{array}{l}\text { Bone } \\
\text { marrow }\end{array}$ & Mouse & a-GalCer & IL-17+ NKT cells $\downarrow ;$ FoxP3+IL-10+ NKT cells $\uparrow$ & $\begin{array}{l}\text { Liver injury } \downarrow \text {; liver inflammatory cell } \\
\text { infiltration } \downarrow\end{array}$ & [73] \\
\hline N/A & $\begin{array}{l}\text { Bone } \\
\text { marrow }\end{array}$ & Mouse & a-GalCer & $\begin{array}{l}\text { CD4+ cells } \downarrow \text {; IL10-producing CD4+CD25+FoxP3+ Tregs } \uparrow \text {; IL-6- } \\
\text { and TNF-a-producing inflammatory B cells } \downarrow \text {; migration of } \\
\text { inflammatory cells from the spleen into the injured livers } \uparrow\end{array}$ & $\begin{array}{l}\text { Serum aminotransferase } \downarrow \text {; tissue } \\
\text { necrosis } \downarrow\end{array}$ & [110 \\
\hline N/A & $\begin{array}{l}\text { Bone } \\
\text { marrow }\end{array}$ & Mouse & LPS & $\begin{array}{l}\text { Liver CD4+ T cell infiltration } \downarrow ; C D 4+T \text { cell activation } \downarrow \text {; total } \\
\text { number of Th1 cells } \uparrow \text {; induction of Tregs and regulatory DCs in } \\
\text { the liver } \uparrow \text {; DC-induced Treg differentiation } \uparrow\end{array}$ & $\begin{array}{l}\text { Liver functions } \uparrow \text {; survival time of ALF } \\
\text { mice } \uparrow\end{array}$ & {$[74]$} \\
\hline N/A & $\begin{array}{l}\text { Bone } \\
\text { marrow }\end{array}$ & Mouse & $\begin{array}{l}\text { Methionine-choli } \\
\text { ne deficient diet }\end{array}$ & $\begin{array}{l}\text { Activation of CD4+IFN- } \gamma+\text { lymphocytes } \downarrow \text {; activation of } \\
\text { CD4+IL- } 6+\text { lymphocytes } \downarrow\end{array}$ & $\begin{array}{l}\text { Weight loss } \downarrow \text {; hepatic lipid } \\
\text { peroxidation } \downarrow \text {; hepatic steatosis } \downarrow \text {; } \\
\text { hepatic lobular inflammation } \downarrow \text {; liver } \\
\text { fibrogenesis } \downarrow\end{array}$ & {$[83]$} \\
\hline N/A & $\begin{array}{l}\text { Adipose } \\
\text { tissue }\end{array}$ & Mouse & $\begin{array}{l}\text { Atherogenic } \\
\text { high-fat diet }\end{array}$ & $\begin{array}{l}\text { The number of intrahepatic infiltrating CD11b+ and Gr- } 1+\text { cells } \\
\text { and the ratio of CD8+/CD4+ cells } \downarrow\end{array}$ & $\begin{array}{l}\text { Engraftment into the liver } \uparrow \text {; albumin } \\
\text { secretion } \uparrow \text {; liver fibrosis } \downarrow\end{array}$ & {$[84]$} \\
\hline N/A & $\begin{array}{l}\text { Umbilical } \\
\text { cord }\end{array}$ & Human & Hepatitis B virus & 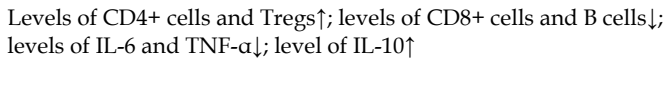 & $\begin{array}{l}\text { Level of aspartate aminotransferase } \downarrow \text {; } \\
\text { levels of albumin and total bilirubin } \\
\text { and the prothrombin time } \uparrow\end{array}$ & [12] \\
\hline N/A & $\begin{array}{l}\text { Bone } \\
\text { marrow }\end{array}$ & Human & Hepatitis B virus & Tregs $\uparrow ;$ Foxp $3 \uparrow ;$ Th17 cells $\downarrow ;$ RORYt $\downarrow$ & Liver function $\uparrow$ & [91] \\
\hline N/A & $\begin{array}{l}\text { Bone } \\
\text { marrow }\end{array}$ & Mouse & $\mathrm{CCl}_{4}$ & $\begin{array}{l}\text { Th17 cells } \downarrow \text {; serum IL-17 level } \downarrow \text {; CD4+IL-10+ T cells } \uparrow \text {; levels of } \\
\text { IL-10, IDO and kynurenine } \uparrow\end{array}$ & Liver functions $\uparrow$; liver fibrosis $\downarrow$ & [89] \\
\hline N/A & $\begin{array}{l}\text { Bone } \\
\text { marrow }\end{array}$ & Rat & $\mathrm{CCl}_{4}$ & $\begin{array}{l}\text { Expression of IL-17, IL-2 and IL- } 6 \text { in serum and expression of } \\
\text { IL-17A and IL-17RA in liver } \downarrow \text {; expression of STAT3, p-STAT3, } \\
\text { P-SMAD3 and TGF- } \beta R 2 \downarrow\end{array}$ & Liver functions $\uparrow$ & {$[90]$} \\
\hline N/A & $\begin{array}{l}\text { Bone } \\
\text { marrow }\end{array}$ & Mouse & $\begin{array}{l}\text { Polyinosinic-poly } \\
\text { cytidylic acid } \\
\text { sodium }\end{array}$ & $\begin{array}{l}\text { CD4+Foxp3+ Tregs in peripheral blood and in lymph nodes } \uparrow \\
\text { serum TGF- } \beta 1 \uparrow ; \text { IFN- } \gamma \downarrow\end{array}$ & Liver recovery $\uparrow$ & [96] \\
\hline N/A & $\begin{array}{l}\text { Bone } \\
\text { marrow }\end{array}$ & Rat & LT & Levels of Th2 cells and Tregs $\uparrow$; number of Th1 and Th17 cells $\downarrow$ & $\begin{array}{l}\text { Acute rejection rate } \downarrow \text {; levels of liver } \\
\text { enzymes and hepatic apoptosis } \downarrow ; \\
\text { survival rate of LT mice } \uparrow\end{array}$ & [99] \\
\hline N/A & $\begin{array}{l}\text { Umbilical } \\
\text { cord }\end{array}$ & Human & LT & Ratio of Tregs and Th17 cells $\uparrow$; levels of TGF- $\beta 1$ and PGE2 $\uparrow$ & $\begin{array}{l}\text { Alanine aminotransferase level } \downarrow ; \\
\text { allograft histology } \uparrow\end{array}$ & {$[100$} \\
\hline $\mathrm{N} / \mathrm{A}$ & $\begin{array}{l}\text { Bone } \\
\text { marrow }\end{array}$ & Rat & LT & $\begin{array}{l}\text { Proliferation of CD4+ T cells } \uparrow \text {; allospecific CTL activity of CD8+ T } \\
\text { cells } \downarrow\end{array}$ & $\begin{array}{l}\text { Survival time of mice that had } \\
\text { undergone LT } \uparrow\end{array}$ & {$[101$} \\
\hline N/A & $\begin{array}{l}\text { Bone } \\
\text { marrow }\end{array}$ & Rat & LT & Treg ratios in peripheral blood $\uparrow$; levels of FoxP3-positive cells $\uparrow$; & $\begin{array}{l}\text { Survival time of rats } \uparrow \text {; typical } \\
\text { LT-related acute graft versus host } \\
\text { disease } \downarrow\end{array}$ & {$[102$} \\
\hline $\begin{array}{l}\text { Overexpression } \\
\text { of PGE2 }\end{array}$ & $\begin{array}{l}\text { Bone } \\
\text { marrow }\end{array}$ & Rat & LT & KC reprogramming $\uparrow$; levels of TNF- $\alpha$ and PGE $2 \uparrow$ & $\begin{array}{l}\text { Allograft tolerance } \uparrow \text {; survival rate of } \\
\text { rats after LT } \uparrow\end{array}$ & [103 \\
\hline $\begin{array}{l}\text { Overexpression } \\
\text { of TGF- } \beta 1\end{array}$ & $\begin{array}{l}\text { Bone } \\
\text { marrow }\end{array}$ & Rat & LT & $\begin{array}{l}\text { CD4+Foxp3+Helios- induced Tregs } \uparrow ; \text { Th17 cells } \downarrow \text {; } \\
\text { immunosuppressive effects in local liver grafts } \uparrow\end{array}$ & $\begin{array}{l}\text { Acute rejection rate after } \mathrm{LT} \downarrow ; \\
\text { mortality of rats after LT } \downarrow \text {; survival of } \\
\text { rats after LT } \uparrow\end{array}$ & [104 \\
\hline $\begin{array}{l}\text { Overexpression } \\
\text { of HO-1 }\end{array}$ & $\begin{array}{l}\text { Bone } \\
\text { marrow }\end{array}$ & Rat & Reduced-size LT & Activity of NK cells $\downarrow$; proportion of regulatory T cells (Tregs) $\uparrow$ & $\begin{array}{l}\text { Median survival time } \uparrow \text {; rejection } \\
\text { activity index } \uparrow\end{array}$ & {$[106$} \\
\hline $\begin{array}{l}\text { Overexpression } \\
\text { of HO-1 }\end{array}$ & $\begin{array}{l}\text { Bone } \\
\text { marrow }\end{array}$ & & LT & $\begin{array}{l}\text { Levels of peripheral Tregs and anti-inflammatory cytokine (IL-10 } \\
\text { and TGF- } \beta \text { ) levels } \uparrow \text {; NK cell activity and proinflammatory } \\
\text { cytokine (IL-2, IL-6, IL-17, IL-23, TNF- } \alpha \text {, and IFN- } \gamma \text { ) levels } \downarrow\end{array}$ & $\begin{array}{l}\text { Survival time of rats after } \mathrm{LT} \uparrow ; \\
\text { apoptosis rate of hepatocytes and } \\
\text { degree of rejection } \downarrow\end{array}$ & [107 \\
\hline $\begin{array}{l}\text { Overexpression } \\
\text { of IL-10 }\end{array}$ & $\begin{array}{l}\text { Bone } \\
\text { marrow }\end{array}$ & Rat & LT & $\begin{array}{l}\text { Expression of cytokines (IL-17, IL-23, IL-6, IFN- } \gamma \text { and TNF- } \alpha \text { ) } \downarrow \text {; } \\
\text { ROR } \gamma t \downarrow \text {; expression of IL-10 and TGF- } \beta 1 \uparrow ; \text { FoxP3 } \uparrow\end{array}$ & Mean survival time of rats after $\mathrm{LT} \uparrow$ & [108 \\
\hline $\begin{array}{l}\text { Overexpression } \\
\text { of Foxp3 }\end{array}$ & $\begin{array}{l}\text { Bone } \\
\text { marrow }\end{array}$ & Rat & LT & $\begin{array}{l}\text { Proliferation of allogeneic CD4+ T cells } \downarrow \text {; level of programmed } \\
\text { death ligand } 1 \uparrow ; C D 4+C D 25+\text { Foxp } 3+\text { Tregs } \uparrow\end{array}$ & Donor-specific allograft tolerance $\uparrow$ & {$[105$} \\
\hline
\end{tabular}






Figure 2. MSCs exert immunomodulatory effects in liver diseases through cell-cell interactions and the secretion of anti-inflammatory factors.

Intravenously infused MSCs were phagocytosed in lung tissue, and these multipotent cells migrated from the lungs to other body sites to exert immunomodulatory effects via secretion of programmed death ligand-1 and IL-10 [64]. MSCs are able to switch macrophages from a pro-inflammatory state to an anti-inflammatory state after secretion of prostaglandin E2 (PGE2), TNF-a, stimulated gene/protein 6, IL-6, and indolamine 2,3-dioxygenase (IDO) [65]. On the other hand, MSCs also migrate into liver tissue and decrease the levels of alanine aminotransferase and proinflammatory cytokines and the degree of liver inflammatory cell infiltration by restraining the activation of NK cells and decreasing the expression of natural killer group 2, member D (NKG2D) in liver [66]. Aggarwal et al. showed that MSCs significantly inhibit the secretion of TNF-a by mature type 1 DCs and decrease IFN- $\gamma$ secretion by Th1 and NK cells; however, MSCs significantly upregulated the proportion of Tregs, increased the secretion of IL-10 by mature DC2s and upregulated the secretion of IL-4 by Th2 cells [67]. They effectively inhibited $\mathrm{T}$ cell proliferation to induce an immunotolerant state [68] and promoted the development and polarization of naive $\mathrm{T}$ cells into
Tregs [69]. MSCs have been reported to suppress the production and secretion of antibodies and the proliferation of activated B lymphocytes in an IDO-dependent manner [70]. However, the immunomodulatory properties of MSCs vary according to the specific liver disease, and these multipotent cells are molded into an anti-inflammatory role for liver regeneration and immune tolerance.

\section{Immunoregulation of MSCs in treating ALF}

ALF is a life-threatening disease that progresses within 26 weeks and is accompanied by abundant hepatic necrosis, coagulation dysfunction, and mental alterations in patients without preexisting liver cirrhosis. Commonly, chemicals, metabolic substances, infectious pathogens and surgery are used to generate models with acute liver injury or liver failure [71]. The immunoregulation of MSCs for treating ALF is still under exploration in chemically treated animal models.

MSCs significantly decreased the incidence of cell death, hepatocyte cytoplasmic vacuolization and macrophage infiltration, thus improving liver histopathology and prolonging the survival time of 
ALF mice [72]. MSCs significantly attenuated acute liver injury by reducing the total number of IL-17-producing NKT cells without influencing the number of IL-17-producing neutrophils, CD4+ T lymphocytes, and CD8+ T lymphocytes in ALF mice [73]. However, Zhang et al. demonstrated that MSCs significantly decreased liver CD4+ T cell infiltration, CD4+ $\mathrm{T}$ cell activation and the total number of Th1 cells, which was accompanied by the induction of Tregs and regulatory DCs in the liver to attenuate liver injury [74]. Acute liver injury and inflammation recruited the injected MSCs into injured liver sites to suppress the activity of intrahepatic TNF-a-, IFN- $\gamma-$, and IL-4-producing NKT cells and increase the serum level of IL-10, which subsequently ameliorated liver damage in a time- and dose-dependent manner [75]. In addition, MSCs also inhibited the accumulation of $\mathrm{CD} 11 \mathrm{~b}+, \mathrm{Gr}-1+$, and F4/80+ cells but increased the number of Tregs in the liver of mice with acute hepatitis [76, 77].

In addition to transplantation of MSCs alone, ALF may be synergistically eliminated by enhancing growth-related gene expression to block the effect of inflammatory factors. For example, IL-35-overexpressing MSCs inhibited the secretion of IFN- $\gamma$ in liver mononuclear cells via regulation of the JAK-1-STAT-1/STAT-4 signaling pathway, thus protecting against hepatocyte apoptosis in acute fulminant hepatitis [78]. To this end, MSCs transformed the body into an anti-inflammatory state after upregulating anti-inflammatory immune cells in the serum and liver, thus reducing the hepatocyte apoptosis rate and promoting the liver regeneration process in ALF models.

\section{Immunoregulation of MSCs in treating NAFLD and liver fibrosis}

NAFLD happens in individuals with no history of alcohol abuse and is accompanied by the accumulation of excessive fat in the liver. The development of NAFLD is attributed to metabolic factors and genetics, and the disease can progress into nonalcoholic steatohepatitis, hepatic fibrosis, liver cirrhosis and hepatoma [79].

Immune cells, including macrophages, NK cells, and $\mathrm{T}$ cells, participate in the progression of NAFLD and serve as potential therapeutic targets. Diminishing the resident $\mathrm{KCs}$ and recruited bone marrow-derived macrophages led to systemic insulin resistance and $\mathrm{NASH}$, which indicates the importance of macrophages in prohibiting the development of NAFLD [80]. Cur et al. demonstrated that the initiation of hepatocyte apoptosis in NASH patients activated NK cells in a NKG2D-dependent manner; these NK cells contribute to reversing liver fibrosis by inhibiting and killing HSCs [81]. In addition, apoptosis of liver NKT cells also contributes to insulin resistance and steatosis in NAFLD [82]. MSC transplantation decreased high-fat diet-induced weight gain, steatosis, lobular inflammation and liver fibrogenesis in mice with NAFLD via inhibition of splenic CD4+IFN- $\gamma^{+}$and CD4+IL-6+ T lymphocyte differentiation, while it had no effect on the activity of CD4+IL-17+ $T$ lymphocytes [83]. Seki et al. demonstrated that MSCs engrafted into the liver and restored albumin secretion in a NASH model by reducing the number of intrahepatic infiltrating $\mathrm{CD} 11 \mathrm{~b}+$ and Gr-1+ cells and the ratio of CD8+/CD4+ cells [84].

In addition to NAFLD, other factors, including the hepatitis virus, alcohol consumption, cholangitis and autoimmune hepatitis, result in the accumulation of aberrant myofibroblasts and extracellular matrix in the liver and subsequent liver fibrosis and are associated with poor prognosis [85]. Monocytes, the precursors of fibrocytes, macrophages and DCs, are vital to the progression of liver fibrosis. IL-4 and IL-13 derived from activated CD4+ T cells can stimulate the differentiation of fibrogenic myeloid cells and macrophages in liver tissue. Moreover, the secretion of IL-17A from Th17 cells further activates myofibroblasts directly and indirectly. In addition to these fibrogenic cells, both Tregs and macrophages are fibrogenic or fibrolytic during fibrosis progression and fibrosis reversal [86]. However, KCs can generate matrix metalloproteinases and promote matrix degradation to resolve liver injury and fibrosis [87, 88]. MSCs significantly attenuated $\mathrm{CCl}_{4}$-induced liver fibrosis by decreasing the percentage of Th17 cells and increasing CD4+IL-10+ $\mathrm{T}$ cells and immunosuppressive factors including IL-10, IDO and kynurenine [89]. MSC transplantation reversed liver fibrosis by downregulating the serum levels of IL-17, IL-2 and IL- 6 and the expression of IL-17A and IL-17RA in the liver, which was accompanied by downregulation of the expression of STAT3, p-STAT3, P-SMAD3 and TGF- $\beta$ R2 [90].

In addition, MSCs also improved liver function and clinical symptoms in patients with liver fibrosis via attenuation of pro-inflammatory responses and improved anti-inflammatory responses. Administration of MSCs significantly downregulated the levels of IL-6 and TNF-a but upregulated the level of IL-10 in patients with hepatitis B virus-induced decompensated liver cirrhosis after 2 and 4 weeks. Moreover, MSCs also increased the levels of CD4+ T cells and Tregs but decreased the levels of CD8+ T cells and B cells. Although MSCs did not attenuate the development of liver failure compared with standard treatments, they remarkably decreased the level of 
aspartate aminotransferase and improved the levels of albumin and total bilirubin and the prothrombin time [12]. When added to entecavir treatment, autologous MSCs further improved liver function in hepatitis B virus-induced liver cirrhosis patients. Moreover, MSCs significantly increased the levels of Tregs and Foxp3 but decreased the levels of Th17 cells and retinoic acid receptor-related orphan receptor gamma $t$ (ROR $y t)$. MSCs also improved the serum TGF- $\beta$ level but decreased the levels of serum IL-17, TNF- $\alpha$, and IL-6 [91].

Patients with primary biliary cirrhosis (PBC), a kind of prototypical autoimmune disease, have a higher number of autoreactive liver-infiltrating CD4+ $\mathrm{T}$ cells and CD8+ $\mathrm{T}$ cells in their livers than in their blood [92, 93]. In addition, activated NKT cells enhance the death of biliary epithelial cells, which leads to the progression of PBC [94]. Intriguingly, MSC transplantation significantly alleviated symptoms of fatigue and pruritus in most patients who responded only partially to ursodeoxycholic acid treatment [95]. Moreover, allogeneic MSC transplantation significantly increased the level of CD4+Foxp3+ Tregs in peripheral blood and in lymph nodes in a PBC animal model, thus inhibiting the systemic immune response and enhancing liver recovery from liver inflammation in $\mathrm{PBC}$ mice [96]. As we know, few studies have focused on the potential mechanisms of MSC transplantation in the attenuation of liver injury in $\mathrm{PBC}$, and it is necessary to expand related studies for clinical applications.

\section{Immunoregulation of MSCs in recipients who have undergone LT}

LT is the standard therapy for patients with end-stage liver diseases, while discontinuation of immunosuppression when the native liver regenerates after LT may lead to spontaneous rejection and atrophy of the allogeneic liver graft [97]. Acute rejection after LT is usually treated with large doses of immunosuppressants with severe toxicity and side effects, so it is imperative to find a safe and effective method for preventing rejection in individuals with LT. In this regard, immunomodulatory cell therapy is an innovative approach to complement standard pharmacotherapy in LT recipients. Since MSCs exert immunomodulatory and regenerative effects in vivo, they effectively prolong organ allograft survival and reduce the side effects of transplantation and concomitant therapy.

Following LT, the initiation of liver graft rejection is accompanied by upregulation of peripheral blood Th1 cells, while the upregulation of Th2 cells indicates long-term acceptance or tolerance of transplanted livers [98]. The infusion of MSCs upregulated the levels of Th2 cells and Tregs but decreased Th1 and Th17 cells, consequently reducing the expression of IL-2, IL-6, IL-17, IL-23, IFN- $\gamma$ and TNF- $\alpha$ and increasing the concentrations of IL-10 and TGF- $\beta$ in rats after LT. To this end, MSC administration protected against liver dysfunction and hepatic apoptosis and significantly decreased the acute rejection rate and improved the survival rate in LT rats [99]. In contrast to the side effects seen with general therapy with conventional immunosuppressive agents, Shi et al. observed no side effects of MSC transplantation in LT patients, and they found that MSC infusions markedly downregulated alanine aminotransferase levels and improved allograft histology throughout the 12-week follow-up. However, they argued that MSCs effectively increased the ratio of Tregs and Th17 cells and the related cytokines (TGF- $\beta 1$ and PGE2) after 4 weeks [100]. In addition, MSCs prolonged the survival of mice that had undergone LT by increasing the expression of FoxP3 and CTLA-4 and decreasing the proliferation of CD4+ T cells and the allospecific CTL activity of CD8+ $\mathrm{T}$ cells [101]. However, the administration time of MSCs will influence the effects in attenuating liver graft rejection. Xia et al. highlighted that only MSC administration early after LT prolonged the survival time of rats and inhibited the typical LT-related acute graft versus host disease (aGVHD) compared with MSC transplantation from day 8 to day 14 in rats [102].

A variety of key genes are overexpressed in MSCs to enhance their immunoregulatory capacities and improve LT prognosis. After coculture with KCs, MSCs downregulated the levels of pro-inflammatory cytokines, such as IL-1 $\beta$ and IL-6 while upregulating the levels of anti-inflammatory cytokines, such as TGF- $\beta$, IL-4, PGE2 and IL-10. Moreover, PGE2overexpressing MSCs and TGF- $\beta 1$-overexpressing MSCs more significantly increased the allograft tolerance and improved the survival of rats after LT [103, 104]. Foxp3-overexpressing MSCs generated a state of Treg-dependent tolerance and induced donor-specific allograft tolerance in a contact-dependent mechanism [105]. Transplantation of heme oxygenase (HO)-1-overexpressing MSCs significantly decreased the rejection rate while increasing the survival time of LT rats by increasing the levels of peripheral Tregs and decreasing the levels of NK cells in liver tissue [106, 107]. Furthermore, overexpression of HO-1 or IL-10 in MSCs significantly increased the levels of anti-inflammatory cytokines (IL-10 and TGF- $\beta$ ) and decreased the levels of proinflammatory cytokines (IL-2, IL-6, IL-17, IL-23, TNF- $\alpha$, and IFN- $\gamma$ ) in LT recipients [106-108]. Gene modification of MSCs will 
further contribute to the inhibition of LT rejection since multiple cytokines participate in MSC immunoregulation in vivo. However, it is worth mentioning that gene modification may induce epigenetic changes or gene mutations in MSCs, potentially leading to tumor generation in vivo.

\section{Conclusions and Future Directions}

Immune cell infiltration is an essential step leading to liver injury, which is accompanied by hepatocyte apoptosis, HSC activation, uncontrolled wound-healing pathophysiology, formation of intrahepatic scar tissue and tumorigenesis. As previously reported, MSCs are able to migrate toward injured tissues, undergo hepatogenic differentiation, inhibit inflammatory factor release and enhance the proliferation of liver cells in vivo. Although the application of MSCs is extensive in inflammationrelated liver diseases, the elucidation of the molecular mechanisms underlying the interactions between MSCs and immune cells can further help us to develop new MSC-based therapies for treating liver diseases. MSCs inhibit the activation of proinflammatory immune cells but enhance the activation of anti-inflammatory immune cells to generate an immunotolerant microenvironment in liver tissue. It is worth mentioning that gene modification of these cytokines may help to improve the therapeutic effects of MSC transplantation in liver diseases but could lead to potential tumorigenesis. As we have discussed, MSC transplantation is an effective anti-inflammatory strategy for eliminating acute or chronic liver injury and has great potential for application in liver regenerative medicine.

\section{Abbreviations}

KCs, Kupffer cells; HSCs, hepatic stellate cells; DCs, dendritic cells; NK, natural killer; NKT, natural killer T; LT, liver transplantation; MSC, mesenchymal stromal cell; Tregs, regulatory $\mathrm{T}$ cells; Bregs, regulatory B cells; ALF, acute liver failure; NAFLD, nonalcoholic fatty liver disease; ILCs, innate lymphoid cells; TNF- $\alpha$, tumor necrosis factor- $\alpha$; IL, interleukin; IFN, interferon; pDCs, plasmacytoid DCs; cDCs, classical DCs; NASH, nonalcoholic steatohepatitis; PGE2, prostaglandin E2; IDO, indolamine 2,3-dioxygenase; NKG2D, natural killer group 2, member $\mathrm{D} ; \mathrm{CCl}_{4}$, carbon tetrachloride; TAA, thioacetamide; ConA, concanavalin A; a-GalCer, a-galactosylceramide; LPS, lipopolysaccharide; iNOS, inducible nitric oxide synthase; FoxP3, forkhead box protein 3; RORYt, retinoic acid receptor-related orphan receptor gamma $t$; $\mathrm{PBC}$, primary biliary cirrhosis; aGVHD, acute graft versus host disease; $\mathrm{HO}$, heme oxygenase.

\section{Acknowledgments}

This work was supported by the National Natural Science Foundation of China (No. 81700553), the Basic public welfare research project of Zhejiang province (No. LGF20H030008), the Postdoctoral Research Foundation of China (No. 2017M183789).

\section{Competing Interests}

The authors have declared that no competing interest exists.

\section{References}

1. Michalopoulos GK, DeFrances MC. Liver regeneration. Science. 1997; 276: 60-6.

2. $\mathrm{Hu} \mathrm{C}, \mathrm{Li} \mathrm{L}$. In vitro culture of isolated primary hepatocytes and stem cell-derived hepatocyte-like cells for liver regeneration. Protein \& cell. 2015; 6: 562-74.

3. Fausto N. Liver regeneration and repair: hepatocytes, progenitor cells, and stem cells. Hepatology. 2004; 39: 1477-87.

4. Lee YA, Wallace MC, Friedman SL. Pathobiology of liver fibrosis: a translational success story. Gut. 2015; 64: 830-41.

5. Stravitz RT, Kramer DJ. Management of acute liver failure. Nat Rev Gastroenterol Hepatol. 2009; 6: 542-53.

6. Bieghs V, Trautwein C. The innate immune response during liver inflammation and metabolic disease. Trends Immunol. 2013; 34: 446-52.

7. Jenne CN, Kubes P. Immune surveillance by the liver. Nat Immunol. 2013; 14 : 996-1006.

8. Bernardi M, Gitto S, Biselli M. The MELD score in patients awaiting liver transplant: strengths and weaknesses. J Hepatol. 2011; 54: 1297-306.

9. Kobolak J, Dinnyes A, Memic A, Khademhosseini A, Mobasheri A. Mesenchymal stem cells: Identification, phenotypic characterization, biological properties and potential for regenerative medicine through biomaterial micro-engineering of their niche. Methods. 2016; 99: 62-8.

10. Pittenger MF, Mackay AM, Beck SC, Jaiswal RK, Douglas R, Mosca JD, et al. Multilineage potential of adult human mesenchymal stem cells. Science. 1999; 284: 143-7.

11. Zheng J, Li H, He L, Huang Y, Cai J, Chen L, et al. Preconditioning of umbilical cord-derived mesenchymal stem cells by rapamycin increases cell migration and ameliorates liver ischaemia/reperfusion injury in mice via the CXCR4/CXCL12 axis. Cell Prolif. 2019; 52: e12546.

12. Fang $X$, Liu L, Dong J, Zhang J, Song H, Song Y, et al. A study about immunomodulatory effect and efficacy and prognosis of human umbilical cord mesenchymal stem cells in patients with chronic hepatitis B-induced decompensated liver cirrhosis. Journal of gastroenterology and hepatology. 2018; 33: 774-80.

13. Nahar S, Nakashima Y, Miyagi-Shiohira C, Kinjo T, Toyoda Z, Kobayashi N, et al. Cytokines in adipose-derived mesenchymal stem cells promote the healing of liver disease. World J Stem Cells. 2018; 10: 146-59.

14. Zhou $\mathrm{R}, \mathrm{Li} \mathrm{Z}, \mathrm{He} \mathrm{C}, \mathrm{Li} \mathrm{R}$, Xia H, Li C, et al. Human umbilical cord mesenchymal stem cells and derived hepatocyte-like cells exhibit similar therapeutic effects on an acute liver failure mouse model. PloS one. 2014; 9: e104392.

15. Tao XR, Li WL, Su J, Jin CX, Wang XM, Li JX, et al. Clonal mesenchymal stem cells derived from human bone marrow can differentiate into hepatocyte-like cells in injured livers of SCID mice. Journal of cellular biochemistry. 2009; 108 : 693-704.

16. Banas A, Teratani T, Yamamoto Y, Tokuhara M, Takeshita F, Osaki M, et al. Rapid hepatic fate specification of adipose-derived stem cells and their therapeutic potential for liver failure. Journal of gastroenterology and hepatology. 2009; 24: 70-7.

17. Tautenhahn HM, Bruckner S, Baumann S, Winkler S, Otto W, von Bergen M, et al. Attenuation of Postoperative Acute Liver Failure by Mesenchymal Stem Cell Treatment Due to Metabolic Implications. Annals of surgery. 2016; 263: 546-56.

18. di Bonzo LV, Ferrero I, Cravanzola C, Mareschi K, Rustichell D, Novo E, et al. Human mesenchymal stem cells as a two-edged sword in hepatic regenerative medicine: engraftment and hepatocyte differentiation versus profibrogenic potential. Gut. 2008; 57: 223-31.

19. Volarevic V, Nurkovic J, Arsenijevic N, Stojkovic M. Concise review: Therapeutic potential of mesenchymal stem cells for the treatment of acute liver failure and cirrhosis. Stem cells (Dayton, Ohio). 2014; 32: 2818-23.

20. Meirelles Lda S, Fontes AM, Covas DT, Caplan AI. Mechanisms involved in the therapeutic properties of mesenchymal stem cells. Cytokine \& growth factor reviews. 2009; 20: 419-27.

21. Zhao X, Shi X, Zhang Z, Ma H, Yuan X, Ding Y. Combined treatment with MSC transplantation and neutrophil depletion ameliorates 
D-GalN/LPS-induced acute liver failure in rats. Clinics and research in hepatology and gastroenterology. 2016; 40: 730-8.

22. Yoshizumi Y, Yukawa H, Iwaki R, Fujinaka S, Kanou A, Kanou Y, et al. Immunomodulatory Effects of Adipose Tissue-Derived Stem Cells on Concanavalin A-Induced Acute Liver Injury in Mice. Cell medicine. 2017; 9: 21-33.

23. Driscoll J, Patel T. The mesenchymal stem cell secretome as an acellular regenerative therapy for liver disease. Journal of gastroenterology. 2019; 54 : 763-73.

24. Wang J, Kubes P. A Reservoir of Mature Cavity Macrophages that Can Rapidly Invade Visceral Organs to Affect Tissue Repair. Cell. 2016; 165: 668-78.

25. Melgar-Lesmes P, Edelman ER. Monocyte-endothelial cell interactions in the regulation of vascular sprouting and liver regeneration in mouse. J Hepatol. 2015; 63: 917-25.

26. Fernandez V, Reyes S, Bravo S, Sepulveda R, Romanque P, Santander G, et al. Involvement of Kupffer cell-dependent signaling in T3-induced hepatocyte proliferation in vivo. Biol Chem. 2007; 388: 831-7.

27. Ju C, Tacke F. Hepatic macrophages in homeostasis and liver diseases: from pathogenesis to novel therapeutic strategies. Cell Mol Immunol. 2016; 13: 316-27.

28. Cressman DE, Greenbaum LE, DeAngelis RA, Ciliberto G, Furth EE, Poli V, et al. Liver failure and defective hepatocyte regeneration in interleukin-6-deficient mice. Science. 1996; 274: 1379-83.

29. Sun $\mathrm{H}$, Sun $\mathrm{C}$, Tian $Z$, Xiao W. NK cells in immunotolerant organs. Cell Mol Immunol. 2013; 10: 202-12.

30. Sun R, Gao B. Negative regulation of liver regeneration by innate immunity (natural killer cells/interferon-gamma). Gastroenterology. 2004; 127: 1525-39.

31. Vujanovic NL, Polimeno L, Azzarone A, Francavilla A, Chambers WH, Starzl $\mathrm{TE}$, et al. Changes of liver-resident NK cells during liver regeneration in rats. J Immunol. 1995; 154: 6324-38.

32. Kumar V. NKT-cell subsets: promoters and protectors in inflammatory liver disease. J Hepatol. 2013; 59: 618-20.

33. Malhi H, Gores GJ. Cellular and molecular mechanisms of liver injury. Gastroenterology. 2008; 134: 1641-54.

34. Vilarinho S, Ogasawara K, Nishimura S, Lanier LL, Baron JL. Blockade of NKG2D on NKT cells prevents hepatitis and the acute immune response to hepatitis B virus. Proc Natl Acad Sci U S A. 2007; 104: 18187-92.

35. Gao B, Radaeva S, Park O. Liver natural killer and natural killer T cells: immunobiology and emerging roles in liver diseases. J Leukoc Biol. 2009; 86: 513-28.

36. Hosoya S, Ikejima $\mathrm{K}$, Takeda $\mathrm{K}$, Arai $\mathrm{K}$, Ishikawa $\mathrm{S}$, Yamagata $\mathrm{H}$, et al. Innate immune responses involving natural killer and natural killer $\mathrm{T}$ cells promote liver regeneration after partial hepatectomy in mice. Am J Physiol Gastrointest Liver Physiol. 2013; 304: G293-9.

37. Hammerich L, Tacke F. Role of gamma-delta $\mathrm{T}$ cells in liver inflammation and fibrosis. World J Gastrointest Pathophysiol. 2014; 5: 107-13.

38. Rao R, Graffeo CS, Gulati R, Jamal M, Narayan S, Zambirinis CP, et al. Interleukin 17-producing gammadeltaT cells promote hepatic regeneration in mice. Gastroenterology. 2014; 147: 473-84 e2.

39. Rahman AH, Aloman C. Dendritic cells and liver fibrosis. Biochim Biophys Acta. 2013; 1832: 998-1004

40. Castellaneta A, Di Leo A, Francavilla R, Margiotta M, Barone M, Amoruso A, et al. Functional modification of CD11c+ liver dendritic cells during liver regeneration after partial hepatectomy in mice. Hepatology. 2006; 43: 807-16.

41. Wolf JH, Bhatti TR, Fouraschen S, Chakravorty S, Wang L, Kurian S, et al. Heat shock protein 70 is required for optimal liver regeneration after partial hepatectomy in mice. Liver Transpl. 2014; 20: 376-85.

42. Yang Z, Tang T, Wei X, Yang S, Tian Z. Type 1 innate lymphoid cells contribute to the pathogenesis of chronic hepatitis B. Innate Immun. 2015; 21: 665-73.

43. Kudira R, Malinka T, Kohler A, Dosch M, de Aguero MG, Melin N, et al. P2X1-regulated IL-22 secretion by innate lymphoid cells is required for efficient liver regeneration. Hepatology. 2016; 63: 2004-17.

44. Jaeschke H. Mechanisms of Liver Injury. II. Mechanisms of neutrophil-induced liver cell injury during hepatic ischemia-reperfusion and other acute inflammatory conditions. Am J Physiol Gastrointest Liver Physiol. 2006; 290: G1083-8.

45. Kita H. Eosinophils: multifaceted biological properties and roles in health and disease. Immunol Rev. 2011; 242: 161-77.

46. Goh YP, Henderson NC, Heredia JE, Red Eagle A, Odegaard JI, Lehwald N, et al. Eosinophils secrete IL-4 to facilitate liver regeneration. Proc Natl Acad Sci U S A. 2013; 110: 9914-9.

47. Naseem S, Hussain T, Manzoor S. Interleukin-6: A promising cytokine to support liver regeneration and adaptive immunity in liver pathologies. Cytokine \& growth factor reviews. 2018; 39: 36-45.

48. Tumanov AV, Koroleva EP, Christiansen PA, Khan MA, Ruddy MJ, Burnette $\mathrm{B}$, et al. $\mathrm{T}$ cell-derived lymphotoxin regulates liver regeneration. Gastroenterology. 2009; 136: 694-704 e4.

49. Lu L, Feng M, Gu J, Xia Z, Zhang H, Zheng S, et al. Restoration of intrahepatic regulatory $\mathrm{T}$ cells through MMP-9/13-dependent activation of TGF-beta is critical for immune homeostasis following acute liver injury. J Mol Cell Biol. 2013; 5: 369-79.

50. Zhu X, Uetrecht J. A novel T(H)17-type cell is rapidly increased in the liver in response to acetaminophen-induced liver injury: $\mathrm{T}(\mathrm{H}) 17$ cells and the innate immune response. J Immunotoxicol. 2013; 10: 287-91.
51. Behnke $\mathrm{K}$, Zhuang $\mathrm{Y}, \mathrm{Xu}$ HC, Sundaram B, Reich $\mathrm{M}$, Shinde PV, et al. B Cell-Mediated Maintenance of Cluster of Differentiation 169-Positive Cells Is Critical for Liver Regeneration. Hepatology. 2018; 68: 2348-61.

52. Almishri W, Deans J, Swain MG. Rapid activation and hepatic recruitment of innate-like regulatory B cells after invariant NKT cell stimulation in mice. J Hepatol. 2015; 63: 943-51.

53. Kim DH, Je CM, Sin JY, Jung JS. Effect of partial hepatectomy on in vivo engraftment after intravenous administration of human adipose tissue stromal cells in mouse. Microsurgery. 2003; 23: 424-31.

54. Khuu DN, Nyabi O, Maerckx C, Sokal E, Najimi M. Adult human liver mesenchymal stem/progenitor cells participate in mouse liver regeneration after hepatectomy. Cell transplantation. 2013; 22: 1369-80.

55. Wabitsch S, Benzing C, Krenzien F, Splith K, Haber PK, Arnold A, et al. Human Stem Cells Promote Liver Regeneration After Partial Hepatectomy in BALB/C Nude Mice. The Journal of surgical research. 2019; 239: 191-200.

56. Liu Y, Yang F, Li J, Wang J, Wang X, Zhang Y, et al. Mesenchymal Stem Cells Enhance Liver Regeneration via Improving Lipid Accumulation and Hippo Signaling. Stem cells international. 2018; 2018: 7652359.

57. Okay E, Simsek T, Subasi C, Gunes A, Duruksu G, Gurbuz Y, et al. Cross effects of resveratrol and mesenchymal stem cells on liver regeneration and homing in partially hepatectomized rats. Stem cell reviews and reports. 2015; 11: 322-31.

58. Ding HR, Wang JL, Tang ZT, Wang Y, Zhou G, Liu Y, et al. Mesenchymal Stem Cells Improve Glycometabolism and Liver Regeneration in the Treatment of Post-hepatectomy Liver Failure. Frontiers in physiology. 2019; 10: 412.

59. Liu ZC, Chang TM. Preliminary study on intrasplenic implantation of artificial cell bioencapsulated stem cells to increase the survival of $90 \%$ hepatectomized rats. Artificial cells, blood substitutes, and immobilization biotechnology. 2009; 37: 53-5.

60. Fouraschen SM, Pan Q, de Ruiter PE, Farid WR, Kazemier G, Kwekkeboom J, et al. Secreted factors of human liver-derived mesenchymal stem cells promote liver regeneration early after partial hepatectomy. Stem cells and development. 2012; 21: 2410-9.

61. Liu $\mathrm{T}, \mathrm{Mu} \mathrm{H}$, Shen $\mathrm{Z}$, Song Z, Chen X, Wang Y. Autologous adipose tissuederived mesenchymal stem cells are involved in rat liver regeneration following repeat partial hepatectomy. Molecular medicine reports. 2016; 13: 2053-9.

62. Saidi RF, Rajeshkumar B, Shariftabrizi A, Bogdanov AA, Zheng S, Dresser K, et al. Human adipose-derived mesenchymal stem cells attenuate liver ischemia-reperfusion injury and promote liver regeneration. Surgery. 2014; 156: $1225-31$

63. Ezquer F, Bahamonde J, Huang YL, Ezquer M. Administration of multipotent mesenchymal stromal cells restores liver regeneration and improves liver function in obese mice with hepatic steatosis after partial hepatectomy. Stem cell research \& therapy. 2017; 8: 20.

64. de Witte SFH, Luk F, Sierra Parraga JM, Gargesha M, Merino A, Korevaar SS, et al. Immunomodulation By Therapeutic Mesenchymal Stromal Cells (MSC) Is Triggered Through Phagocytosis of MSC By Monocytic Cells. Stem cells (Dayton, Ohio). 2018; 36: 602-15.

65. Gazdic M, Volarevic V, Arsenijevic N, Stojkovic M. Mesenchymal stem cells: a friend or foe in immune-mediated diseases. Stem Cell Rev. 2015; 11: 280-7.

66. Ou M, Yuan X, Liu D, Ma Y, Zhu J, Cui J, et al. Bone Marrow-Derived Mesenchymal Stem Cells Attenuate Immune-Mediated Liver Injury and Compromise Virus Control During Acute Hepatitis B Virus Infection in Mice. Stem cells and development. 2017; 26: 818-27.

67. Aggarwal S, Pittenger MF. Human mesenchymal stem cells modulate allogeneic immune cell responses. Blood. 2005; 105: 1815-22.

68. Kitazawa Y, Li XK, Xie L, Zhu P, Kimura H, Takahara S. Bone marrow-derived conventional, but not cloned, mesenchymal stem cells suppress lymphocyte proliferation and prevent graft-versus-host disease in rats. Cell transplantation. 2012; 21: 581-90.

69. Svobodova E, Krulova M, Zajicova A, Pokorna K, Prochazkova J, Trosan P, et al. The role of mouse mesenchymal stem cells in differentiation of naive T-cells into anti-inflammatory regulatory T-cell or proinflammatory helper T-cell 17 population. Stem cells and development. 2012; 21: 901-10.

70. Volarevic V, Arsenijevic N, Lukic ML, Stojkovic M. Concise review: Mesenchymal stem cell treatment of the complications of diabetes mellitus. Stem cells (Dayton, Ohio). 2011; 29: 5-10.

71. Wu Z, Han M, Chen T, Yan W, Ning Q. Acute liver failure: mechanisms of immune-mediated liver injury. Liver Int. 2010; 30: 782-94.

72. Huang B, Cheng X, Wang H, Huang W, la Ga Hu Z, Wang D, et al. Mesenchymal stem cells and their secreted molecules predominantly ameliorate fulminant hepatic failure and chronic liver fibrosis in mice respectively. J Transl Med. 2016; 14: 45.

73. Milosavljevic N, Gazdic M, Simovic Markovic B, Arsenijevic A, Nurkovic J, Dolicanin $Z$, et al. Mesenchymal stem cells attenuate acute liver injury by altering ratio between interleukin 17 producing and regulatory natural killer $\mathrm{T}$ cells. Liver Transpl. 2017; 23: 1040-50.

74. Zhang $Y$, Cai $W$, Huang $Q$, Gu Y, Shi $Y$, Huang J, et al. Mesenchymal stem cells alleviate bacteria-induced liver injury in mice by inducing regulatory dendritic cells. Hepatology. 2014; 59: 671-82.

75. Gazdic M, Simovic Markovic B, Vucicevic L, Nikolic T, Djonov V, Arsenijevic $\mathrm{N}$, et al. Mesenchymal stem cells protect from acute liver injury by attenuating hepatotoxicity of liver natural killer $\mathrm{T}$ cells in an inducible nitric oxide 
synthase- and indoleamine 2,3-dioxygenase-dependent manner. J Tissue Eng Regen Med. 2018; 12: e1173-e85.

76. Higashimoto M, Sakai Y, Takamura M, Usui S, Nasti A, Yoshida K, et al. Adipose tissue derived stromal stem cell therapy in murine ConA-derived hepatitis is dependent on myeloid-lineage and CD4+ T-cell suppression. Eur J Immunol. 2013; 43: 2956-68.

77. Tamura R, Uemoto S, Tabata Y. Immunosuppressive effect of mesenchymal stem cell-derived exosomes on a concanavalin A-induced liver injury model. Inflamm Regen. 2016; 36: 26.

78. Wang W, Guo H, Li H, Yan Y, Wu C, Wang X, et al. Interleukin-35 Gene-Modified Mesenchymal Stem Cells Protect Concanavalin A-Induced Fulminant Hepatitis by Decreasing the Interferon Gamma Level. Hum Gene Ther. 2018; 29: 234-41.

79. Ahmed M. Non-alcoholic fatty liver disease in 2015. World J Hepatol. 2015; 7: $1450-9$

80. Odegaard JI, Ricardo-Gonzalez RR, Red Eagle A, Vats D, Morel CR, Goforth $\mathrm{MH}$, et al. Alternative M2 activation of Kupffer cells by PPARdelta ameliorates obesity-induced insulin resistance. Cell Metab. 2008; 7: 496-507.

81. Muhanna N, Abu Tair L, Doron S, Amer J, Azzeh M, Mahamid M, et al. Amelioration of hepatic fibrosis by NK cell activation. Gut. 2011; 60: 90-8

82. Kremer M, Thomas E, Milton RJ, Perry AW, van Rooijen N, Wheeler MD, et al. Kupffer cell and interleukin-12-dependent loss of natural killer $\mathrm{T}$ cells in hepatosteatosis. Hepatology. 2010; 51: 130-41.

83. Wang H, Wang D, Yang L, Wang Y, Jia J, Na D, et al. Compact bone-derived mesenchymal stem cells attenuate nonalcoholic steatohepatitis in a mouse model by modulation of CD4 cells differentiation. Int Immunopharmacol. 2017; 42: 67-73.

84. Seki A, Sakai Y, Komura T, Nasti A, Yoshida K, Higashimoto M, et al. Adipose tissue-derived stem cells as a regenerative therapy for a mouse steatohepatitis-induced cirrhosis model. Hepatology. 2013; 58: 1133-42.

85. $\mathrm{Hu} \mathrm{C}$, Zhao L, Duan J, Li L. Strategies to improve the efficiency of mesenchymal stem cell transplantation for reversal of liver fibrosis. J Cell Mol Med. 2019; 23: 1657-70.

86. Berardis S, Dwisthi Sattwika P, Najimi M, Sokal EM. Use of mesenchymal stem cells to treat liver fibrosis: current situation and future prospects. World J Gastroenterol. 2015; 21: 742-58.

87. Fallowfield JA, Mizuno M, Kendall TJ, Constandinou CM, Benyon RC, Duffield JS, et al. Scar-associated macrophages are a major source of hepatic matrix metalloproteinase-13 and facilitate the resolution of murine hepatic fibrosis. J Immunol. 2007; 178: 5288-95.

88. Pellicoro A, Aucott RL, Ramachandran P, Robson AJ, Fallowfield JA, Snowdon VK, et al. Elastin accumulation is regulated at the level of degradation by macrophage metalloelastase (MMP-12) during experimental liver fibrosis. Hepatology. 2012; 55: 1965-75.

89. Milosavljevic N, Gazdic M, Simovic Markovic B, Arsenijevic A, Nurkovic I, Dolicanin Z, et al. Mesenchymal stem cells attenuate liver fibrosis by suppressing Th17 cells - an experimental study. Transpl Int. 2018; 31: 102-15.

90. Farouk $S$, Sabet $S$, Abu Zahra FA, El-Ghor AA Bone marrow derived-mesenchymal stem cells downregulate IL17A dependent IL6/STAT3 signaling pathway in CCl4-induced rat liver fibrosis. PloS one. 2018; 13: e0206130.

91. Xu L, Gong Y, Wang B, Shi K, Hou Y, Wang L, et al. Randomized trial of autologous bone marrow mesenchymal stem cells transplantation for hepatitis B virus cirrhosis: regulation of Treg/Th17 cells. Journal of gastroenterology and hepatology. 2014; 29: 1620-8.

92. Bernuzzi F, Fenoglio D, Battaglia F, Fravega M, Gershwin ME, Indiveri F, et al. Phenotypical and functional alterations of CD8 regulatory $\mathrm{T}$ cells in primary biliary cirrhosis. J Autoimmun. 2010; 35: 176-80.

93. Hirschfield GM, Gershwin ME. The immunobiology and pathophysiology of primary biliary cirrhosis. Annu Rev Pathol. 2013; 8: 303-30.

94. Aso-Ishimoto Y, Yamagiwa S, Ichida T, Miyakawa R, Tomiyama C, Sato Y, et al. Increased activated natural killer $\mathrm{T}$ cells in the liver of patients with advanced stage primary biliary cirrhosis. Biomed Res. 2014; 35: 161-9.

95. Wang L, Li J, Liu H, Li Y, Fu J, Sun Y, et al. Pilot study of umbilical cord-derived mesenchymal stem cell transfusion in patients with primary biliary cirrhosis. Journal of gastroenterology and hepatology. 2013; 28 Suppl 1: 85-92.

96. Wang D, Zhang H, Liang J, Gu Z, Ma X, Huang J, et al. Effect of allogeneic bone marrow-derived mesenchymal stem cells transplantation in a polyI:C-induced primary biliary cirrhosis mouse model. Clin Exp Med. 2011; 11: $25-32$.

97. Quaglia A, Portmann BC, Knisely AS, Srinivasan P, Muiesan P, Wendon J, et al. Auxiliary transplantation for acute liver failure: Histopathological study of native liver regeneration. Liver Transpl. 2008; 14: 1437-48.

98. Yang ZL, Cheng K, Sun HG, Zou WW, Wu MM. Changes in peripheral blood Th1 and Th2 cells in rat liver transplantation under different immune statuses. Genet Mol Res. 2013; 12: 6939-46.

99. Yang Y, Shen ZY, Wu B, Yin ML, Zhang BY, Song HL. Mesenchymal stem cells improve the outcomes of liver recipients via regulating $C D 4+T$ helper cytokines in rats. Hepatobiliary Pancreat Dis Int. 2016; 15: 257-65.

100. Shi M, Liu Z, Wang Y, Xu R, Sun Y, Zhang M, et al. A Pilot Study of Mesenchymal Stem Cell Therapy for Acute Liver Allograft Rejection. Stem Cells Transl Med. 2017; 6: 2053-61.
101. Niu J, Wang Y, Liu B, Yao Y. Mesenchymal stem cells prolong the survival of orthotopic liver transplants by regulating the expression of TGF-beta1. Turk J Gastroenterol. 2018; 29: 601-9.

102. Xia X, Chen W, Ma T, Xu G, Liu H, Liang C, et al. Mesenchymal stem cells administered after liver transplantation prevent acute graft-versus-host disease in rats. Liver Transpl. 2012; 18: 696-706.

103. You Y, Zhang J, Gong J, Chen Y, Li Y, Yang K, et al. Mesenchymal stromal cell-dependent reprogramming of Kupffer cells is mediated by TNF-alpha and PGE2 and is crucial for liver transplant tolerance. Immunol Res. 2015; 62: 292-305.

104. Tang J, Yang R, Lv L, Yao A, Pu L, Yin A, et al. Transforming growth factor-beta-Expressing Mesenchymal Stem Cells Induce Local Tolerance in a Rat Liver Transplantation Model of Acute Rejection. Stem cells (Dayton, Ohio). 2016; 34: 2681-92.

105. Qi H, Chen G, Huang Y, Si Z, Li J. Foxp3-modified bone marrow mesenchymal stem cells promotes liver allograft tolerance through the generation of regulatory T cells in rats. J Transl Med. 2015; 13: 274.

106. Shen ZY, Wu B, Liu T, Yang Y, Yin ML, Zheng WP, et al. Immunomodulatory effects of bone marrow mesenchymal stem cells overexpressing heme oxygenase-1: Protective effects on acute rejection following reduced-size liver transplantation in a rat model. Cell Immunol. 2017; 313: 10-24

107. Wu B, Song HL, Yang Y, Yin ML, Zhang BY, Cao Y, et al. Improvement of Liver Transplantation Outcome by Heme Oxygenase-1-Transduced Bone Marrow Mesenchymal Stem Cells in Rats. Stem cells international. 2016; 2016: 9235073.

108. Niu J, Yue W, Song Y, Zhang Y, Qi X, Wang Z, et al. Prevention of acute liver allograft rejection by IL-10-engineered mesenchymal stem cells. Clin Exp Immunol. 2014; 176: 473-84.

109. Zhu X, He B, Zhou X, Ren J. Effects of transplanted bone-marrow-derived mesenchymal stem cells in animal models of acute hepatitis. Cell Tissue Res. 2013; 351: 477-86.

110. Gazdic M, Markovic BS, Arsenijevic A, Jovicic N, Acovic A, Harrell CR, et al. Crosstalk between mesenchymal stem cells and $\mathrm{T}$ regulatory cells is crucially important for the attenuation of acute liver injury. Liver Transpl. 2018; 24: 687-702. 